\title{
Green Liquid Membrane: Development and Challenges
}

\section{Tjoon Tow Teng* and Amir Talebi}

School of Industrial Technology, Universiti Sains Malayasia, Malyasia

Wastewaters are a potential source of pollutants causing serious problems to the environment. Liquid membrane is able to remove contaminants in wastewaters [1], among other techniques such as chemical precipitation, coagulation-flocculation, flotation, ion exchange, electro-oxidation and adsorption [2,3]. It has been given considerable attention by researchers due to its outstanding characteristics such as simultaneous pollutants removal and materials recovery in a single unit, non-equilibrium mass transfer, high selectivity, high fluxes, reusability and low energy consumption [4]. Liquid membrane is a process that involves the transport of a solute from an aqueous phase through an immiscible organic phase to another aqueous phase [5]. Organic phase used are usually composed of a carrier and a diluent [6].

The separation process using conventional solid membranes has disadvantages such as low flux rate, low selectivity (because of polymeric membrane characteristic) and fouling. On the other hand, liquid membrane separation methods use conventional petroleum-based organic solvents and carriers which are hazardous to the environment.

Liquid membrane can be modified to "green liquid membrane" by using environmentally friendly materials. Vegetable oils (such as coconut or palm oil) as non-toxic and clean solvents can be used instead of regular organic solvents and are capable of reducing the amount of common toxic and hazardous chemicals using in liquid membrane methods.

Briefly, the main mechanism of solute transport in liquid membrane loaded only with organic solvent is based on diffusion. The solute species or in better word pollutants dissolve in the liquid membrane and diffuse across the membrane due to concentration gradient. Solute solubility plays a key role in passing through liquid membrane. The solute does not react chemically with the organic solvents and is supposed to be in the same form in the feed phase, organic phase and stripping phase [7]. Selectivity which is one of the advantages of liquid membrane technology can be achieved at reaction of the solute with components of the stripping solution and is directly related to the carriers-mediated (facilitated) transport [8].

The solute transport can be described by subsequent partitioning, complexation and diffusion. Solute, partitioning (dissolving) in liquid membrane on a feed phase and liquid membrane interface reacts with a carrier dissolved in the organic solvent, to form complex. The reverse reaction of this complex in the liquid membrane and stripping phase interface releases the solute which partitions the stripping phase.

Carriers modify the transport mechanism in liquid membranes. Tributylphosphate (TBP) or di-2-ethylhexylphosphoric acid (D2EHPA), the most used carriers in liquid membrane technique, have shown a relatively good efficiency in various dyes or heavy metals removal. However, the new generation of carriers for selective transport of neutral molecules, anions, cations, or zwitterionic species has undergone intensive development in the last two decades. Carrier-assisted transport through liquid membranes is one of the important applications of supramolecular chemistry. Researchers in supramolecular chemistry field have been working to produce spectacular molecules like series of calixarene-based derivatives and resins that are able to provide a proper binding site, specifically for dye removal [9]. It should be mentioned that although the selective removal of heavy metals is a popular application of facilitated (modified) liquid membrane technology, researchers are facing a challenging issue on selective dye removal due to the complexity of dyes type identification in wastewaters containing dyes mixtures.

Ionic liquids are other promising materials that recently researchers have been working on in order to enhance the ability of solute transportation in liquid membrane technology [10-12]. Ionic liquids are basically salts that are liquid below $100^{\circ} \mathrm{C}$ and consist entirely of ions. They show characteristics such as an extremely low vapor pressure, high thermal stability and certain physico-chemical properties that can be tuned by modifying their chemical structure [13] despite of the fact that using a large amount of ionic liquids as solvent in liquid-liquid extraction process might not be cost effective due to the high cost of ionic liquids compared to conventional organic carriers [14].

The major component in liquid membrane organic phase is the diluent. For use as diluent a liquid should satisfy specific criteria: (i) High solute capacity, (ii) Inert toward extraction system, (iii) Wide range of miscibility with carrier, Immiscible with aqueous phase, (iv) Have a low surface tension for good dispersion and coalescence performance, (v) Low viscosity, vapor pressure and freezing point, (vi) Nontoxic and non-corrosive, (vii) Reduce the tendency of carriers to emulsify with the aqueous feed, (viii) improve dispersion and coalescence [15].

Although the present liquid membranes have proved to be a reliable and efficient technique, its procedures are time, reagent and labor consuming, uses large volumes of environmentally unsafe and expensive pure solvents and it is sensitive to operation condition. Solvent loss can occur by solubility in the aqueous phase, volatilization, degradation and by loss in crud. Crud is the material resulting from the agitation of an organic phase, an aqueous phase, and fine solid particles to form a stable mixture [16]. On the other hand, the formation of the third phase such as emulsion during the extraction cannot be tolerated in liquid membrane extraction processes. Elimination of a third phase is usually accomplished by addition of modifier to the solvent, or by increasing the temperature of the system.

The solvents, carriers and phase modifiers are invariably diluted in the organic diluents such as kerosene, chloroform, dichloromethane, ndodecane, isododecane, n-decanol, n-heptane, n-hexane, etc. [17]. These petroleum-based diluents, which form the bulk components in

*Corresponding author: Tjoon Tow Teng, School of Industrial Technology, Universit Sains Malayasia, Penanag, 11800, Malyasia; Tel: +604 6532215; Fax: +604 6573678 ; E-mail: ttteng@usm.my

Received July 12, 2012; Accepted July 13, 2012; Published July 15, 2012

Citation: Teng TT, Talebi A (2012) Green Liquid Membrane: Development and Challenges. J Memb Sci Technol 2:e106. doi:10.4172/2155-9589.1000e106

Copyright: ( 2012 Teng TT, et al. This is an open-access article distributed under the terms of the Creative Commons Attribution License, which permits unrestricted use, distribution, and reproduction in any medium, provided the original author and source are credited. 
the organic phase, are usually toxic, non-renewable, non-biodegradable, flammable and volatile in nature [6]. Hence, it is essential to find a suitable replacement for the conventional petroleum-based organic solvents in order to curb the environmental problem.

Using environmentally friendly and green materials (such as vegetable oils), design and modification of the reactor for better and higher results (higher interfacial area for mass transfer), opportunity to study different kinds of liquid membrane methods like bulk liquid membrane (BLM), supported liquid membrane (SLM) or emulsion liquid membrane (ELM) simultaneously (depending on flexibility of the designed reactor) can be considered as the advantages of new generation of green liquid membranes.

Supported Liquid Membranes (SLM) are based on the use of a porous solid membrane (polymer or ceramic) which supports or hold the liquid membrane phase. The pores of the thin solid membrane are completely filled with the liquid membranes and this impregnation produces relatively stable heterogeneous solid-liquid membranes. In some applications the liquid membrane phase may be sandwiched between two porous solid supports (contained liquid membrane). The typical supports used are thin flat sheets or hollow fibers, manufactured from oleophilic polymers. This type of liquid membrane is useful for laboratory scale but low mass transfer rate and stability are its disadvantages. Bulk Liquid Membranes (BLM) are used for fundamental studies without phase dispersion. This system can be carried out in $\mathrm{H}$-tube or U-tube configurations (depending on the solvent density). This method is very useful for laboratory studies but low fluxes due to relatively low interfacial area to volume ratio make the process relatively complex.

The third type of liquid membrane process is based on the formation of a double emulsion and is referred to as emulsion (surfactant) liquid membranes (ELM). This is a three phase system which is stabilized by an emulsifier, which can be up to $5 \%$ or more of the membrane liquid. In operation the membrane emulsion phase is then dispersed into the donor feed solution and the process of mass transfer can take place. In the ELM process the main problems relate to emulsion stability, poor stability incurs partial rupture of the membranes which reduces overall efficiency. The advantages of emulsion liquid membranes are high transfer rate due to large surface area and large scale piloting availability [7].

\section{Conclusion}

The role of technology in the positive aspects of our life is undeniable but at the same time it is easy to count its destructive effects on the environment. The destructive effects of nuclear processes, the pollution generated by factories, cities and in a word, our overly consuming method of life, which reveals nothing but a dark and virulent perspective of our future has led us to the certain stage of environmental red zone. Green liquid membrane technology is proposed as an environmentally friendly treatment method to remove pollutants and recover materials from wastewaters. Using vegetable oils as solvent, diluent and highly modified chemical carriers in these types of liquid membranes apart from being a non-toxic (or at least less toxic) treatment technology can be considered as a highly cost effective method as well. The future of liquid membrane technology must move toward for highly selectivity, high effectiveness, reusability, cost effectiveness and low toxicity! Green liquid membrane can be considered as a solution, provided that membrane technology researchers and scientists hard work leads us to better ideas tightening with novelty and innovation.

\section{References}

1. Agrawal A, Manoj MK, Kumari S, Bagchi D, Kumar V, et al. (2008) Extractive separation of copper and nickel from copper bleed stream by solvent extraction route. Miner Eng 21: 1126-1130.

2. Kurniawan TA, Chan GYS, Lo WH, Babel S (2006) Physico-chemical treatment techniques for wastewater laden with heavy metals. Chem Eng J 118: 83-98.

3. Sud D, Mahajan G, Kaur MP (2008) Agricultural waste material as potentia adsorbent for sequestering heavy metal ions from aqueous solutions-a review. Bioresour Technol 99: 6017-6027.

4. Chang SH, Teng TT, Ismail N, Alkarkhi AF (2011) Selection of design parameters and optimization of operating parameters of soybean oil-based bulk liquid membrane for $\mathrm{Cu}(\mathrm{II})$ removal and recovery from aqueous solutions. J Hazard Mater 190: 197-204

5. Muthuraman G, Teng TT, Cheu Peng Leh, Norli I (2009) Extraction and recovery of methylene blue from industrial wastewater using benzoic acid as an extractant. J Hazard Mater 163: 363-369.

6. Watson JS (1999) Separation Methods for Waste and Environmenta Applications. Marcel Dekker Inc, New York.

7. Kislik VS (2010) Liquid membranes. Elsevier, Amsterdam, P O Box 211 Netherlands

8. Chakraborty M, Bhattacharya C, Datta S (2004) Study of the stability of w/o/wtype emulsion during the extraction of nickel via emulsion liquid membrane. Sep Sci Technol 39: 2609-2625.

9. Gungor O, Yilmaz A, Memon S, Yilmaz M (2008) Evaluation of the performance of calix[8]arene derivatives as liquid phase extraction material for the removal of azo dyes. J Hazard Mater 158: 202-207.

10. Meinderisma GW, Podt AJG, de Haan AB (2005) Selection of ionic liquids for the extraction of aromatic hydrocarbons from aromatic/aliphatic mixtures. Fue Process Technol 87: 59-70.

11. González JMR, Pérez RG, López JCR, Martínez MA (2012) Extraction of Copper(II) ions from aqueous solutions with the ionic liquid 3-butylpyridiniumbis (trifluoromethanesulfonyl) imide. Sep Purif Technol 89: 320-328.

12. Sun X, Ji Y, Guo L, Chen J, Li D (2011) A novel ammonium ionic liquid based extraction strategy for separating scandium from yttrium and lanthanides. Sep Purif Technol 81: 25-30.

13. Fischer L, Falta T, Koellensperger G, Stojanovic A, Kogelnig D, et al. (2011) Ionic liquids for extraction of metals and metal containing compounds from communal and industrial wastewater. Water Res 45: 4601-4614.

14. Matsumoto M, Ohtani T, Kondo K (2007) Comparison of Solvent Extraction and Supported Liquid Membrane Permeation Using an Ionic Liquid for Concentrating Penicillin G. J Membrane Sci 289: 92-96.

15. Cox M. Rydberg J (2004) Introduction to Solvent Extraction. In: Rydberg J, Cox M, Musikas C, Choppin GR Editors, Solvent Extraction Principles and Practice. Marcel Dekker Inc, New York.

16. Ritcey Gordon M. (1992) Development of Industrial Solvent Extraction Processes. Jan Rydberg, Claude Musikas in Gregory R Choppin (Ed.) Principles and Practices of Solvent Extractio., Marcel Dekker, New York.

17. Chang SH, Teng TT, Norli I (2010) Optimization of $\mathrm{Cu}(\mathrm{II})$ Extraction from Aqueous Solutions by Soybean-Oil-Based Organic Solvent Using Response Surface Methodology, Water Air Soil Poll 217: 567-576. 